\title{
Erratum to: Do Childhood Externalizing Disorders Predict Adult Depression? A Meta-Analysis
}

\author{
Annemarie K. Loth • Deborah A. G. Drabick • \\ Ellen Leibenluft • Leslie A. Hulvershorn
}

Published online: 20 May 2014

(C) Springer Science+Business Media New York 2014

Erratum to: Journal of Abnormal Child Psychology

DOI 10.1007/s10802-014-9867-8

In the original published version of this article the spacing for the heading and data points for Figure 2 was incorrect, making the Figure difficult to interpret. A revision of Figure 2 is presented here:

The online version of the original article can be found at http://dx.doi.org/ 10.1007/s10802-014-9867-8.

A. K. Loth $\cdot$ L. A. Hulvershorn $(\bowtie)$

Department of Psychiatry, Indiana University School of Medicine, Riley Hospital for Children, 705 Riley Hospital Drive, Room 4300, Indianapolis, IN 46202, USA

e-mail: lhulvers@iupui.edu

D. A. G. Drabick

Department of Psychology, Temple University, Philadelphia, PA, USA

\section{E. Leibenluft}

Section on Bipolar Spectrum Disorders, Emotion and Development Branch, National Institute of Mental Health, National Institutes of Health, Department of Health and Human Services, Bethesda, MD, USA 


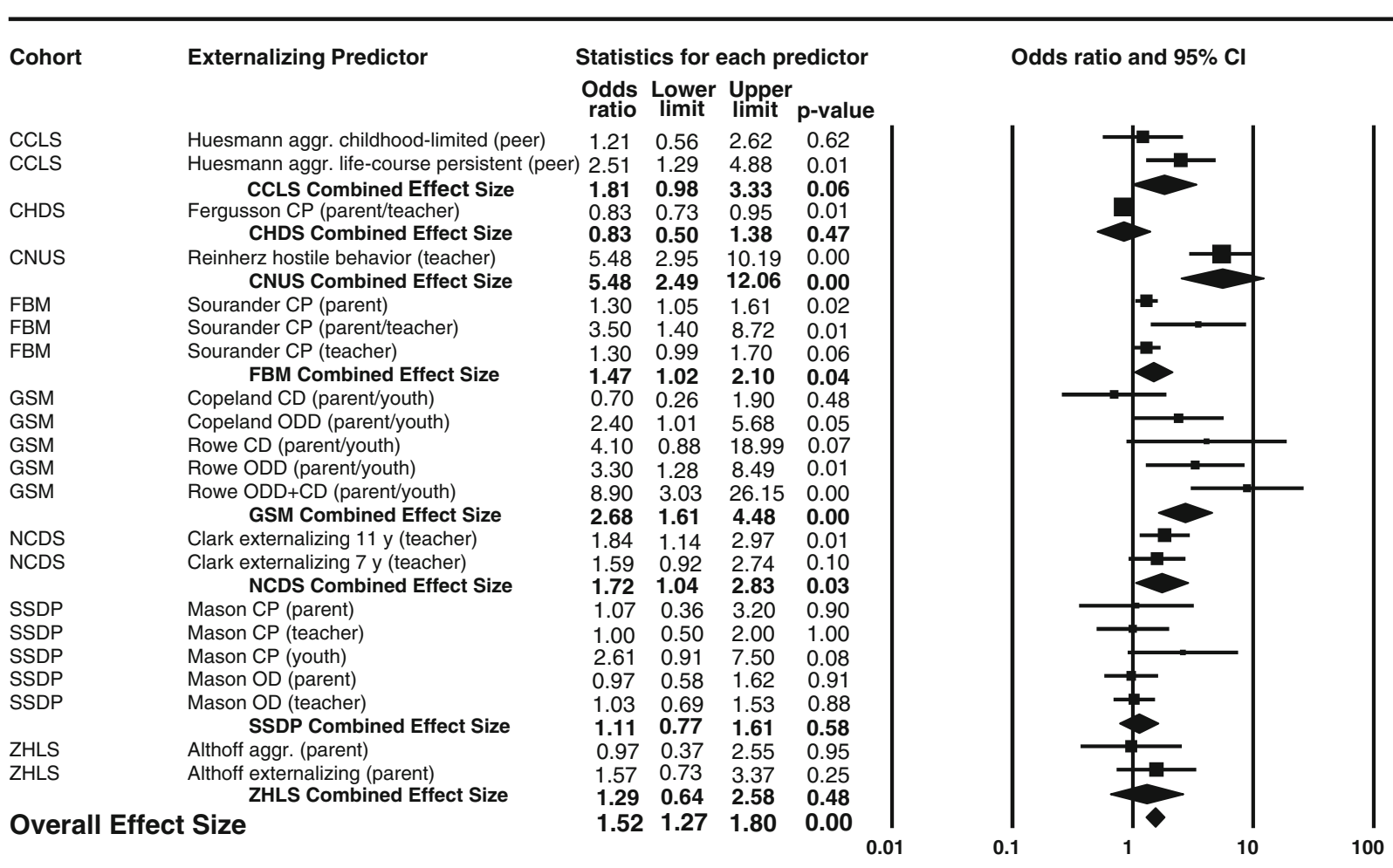

Fig. 2 Childhood externalizing symptoms as predictors of adult depressive disorders. Boxes reflect weights of individual predictors. Effect sizes were combined within cohorts; combined effect sizes are in bold and represented by diamonds. NCDS National Child Development Study, CNUS Community in Northeast US, FBM Finnish Boy to Man, GSM
Great Smoky Mountains, SSDP Seattle Social Development Project, ZHLS Zuid-Holland Longitudinal Study, CCLS Columbia County Longitudinal Study, CHDS Christchurch Health and Development Study, aggr. aggression, $C I$ confidence interval, $C P$ conduct problems, $O D$ oppositional defiant symptoms 